\title{
Influence of Congruity in Store-Attribute Dimensions and Self- Image on Purchase Intentions in Online Stores of Multichannel Retailers
}

Vishag Badrinarayanan

Enrique P. Becerra

Sreedhar Madhavaram

Cleveland State University, s.madhavaram@csuohio.edu

Follow this and additional works at: https://engagedscholarship.csuohio.edu/bus_facpub

Part of the Marketing Commons

How does access to this work benefit you? Let us know!

\section{Publisher's Statement}

NOTICE: this is the author's version of a work that was accepted for publication in Journal of Retailing and Consumer Services. Changes resulting from the publishing process, such as peer review, editing, corrections, structural formatting, and other quality control mechanisms may not be reflected in this document. Changes may have been made to this work since it was submitted for publication. A definitive version was subsequently published in Journal of Retailing and Consumer Services (2014); 10.1016/j.jretconser.2014.01.002

\section{Original Published Citation}

Badrinarayanan, V., Becerra, E. P., Madhavaram, S. (2014). Influence of Congruity in Store-Attribute Dimensions and Self-Image on Purchase Intentions in Online Stores of Multichannel Retailers. Journal of Retailing and Consumer Services.

This Article is brought to you for free and open access by the Monte Ahuja College of Business at EngagedScholarship@CSU. It has been accepted for inclusion in Business Faculty Publications by an authorized administrator of EngagedScholarship@CSU. For more information, please contact library.es@csuohio.edu. 


\title{
Influence of congruity in store-attribute dimensions and self-image on purchase intentions in online stores of multichannel retailers
}

\author{
Vishag Badrinarayanan ${ }^{a, *}$, Enrique P. Becerra ${ }^{a, 1}$, Sreedhar Madhavaram ${ }^{b, 2}$ \\ acCoy College of Business Administration, Texas State University, San Marcos, TX 78666, United States \\ ${ }^{b}$ Monte Ahuja College of Business, Cleveland State University, Cleveland, $\mathrm{OH} 44115$, United States
}

\section{Introduction}

Despite the seemingly pervasive nature of Internet retailers, industry reports emphasize that there still remains tremendous potential for the continued growth of online shopping both within the U.S. and globally (Nielsen, 2010). Global online retail sales continues to demonstrate growth and is expected to reach approximately one trillion dollars in 2013, with online sales in U.S. and Europe accounting for approximately $\$ 260$ billion and $\$ 170$ billion, respectively (Internet Retailer, 2013). However, when comparisons are made regarding consumer behavior and retailer performance across the online stores of multichannel retailers (i.e., erstwhile land-based retailers who have complemented their retail operations by creating their own online stores) and those of pure Internet players, sharp differences emerge. In 2009, online stores of pure Internet players (sales of $\$ 42.9 \mathrm{~B}$ and compounded annual growth rate of $19.89 \%$ ) outpaced those of multichannel retailers (sales of \$49.8 B and compounded annual growth rate of 15.74\%) (Internet Retailer, 2013). A comparison of online performance of leading online retailers in 2012 shows the following discrepancy: Amazon.com generated sales of $\$ 48.1$ billion at a growth rate of $41 \%$, whereas Walmart.com posted sales of approximately $\$ 4.9 \mathrm{~B}$ at a growth rate of $8 \%$ (Businessweek, 2012: Internet Retailer, 2013). As for consumer behavior, it has been reported that

\footnotetext{
* Corresponding author. Tel.: + 1512245 4378; fax: + 15122457475.

E-mail addresses: vbl6(htxstate.edu (V. Badrinarayanan), eb25êtxstate.edu (E.P. Becerra), s.madhavarambircsuohio.edu (S. Madhavaram).

1 Tel.: + 1512245 1277; fax: +1 15122457475

2 Tel: 1216687 3797; fax: 12166875135.
}

less than half of online consumers in the U.S. favor online stores of pure Internet players and only $17 \%$ favor online stores of multichannel retailers (Nielsen, 2010). Needless to say, notwithstanding increased investments in online businesses, sales in online stores represent a very small share of total revenues in large multichannel retailers such as Walmart (2\%), Target (2\%), Macy's (7.2\%), and Sears (8.7\%) (Businessweek, 2012).

These statistics frame the need for researchers to examine the phenomenon of multichannel retailing more rigorously and offer actionable implications to multichannel retailers so that their online stores can compete better against those of pure Internet players. Toward this end, the current study contributes to research on multichannel retailing by identifying three major gaps in the literature and, subsequently, developing and testing an expanded framework of purchase intentions in online stores of multichannel retailers. First, extant research on online stores of multichannel retailers has employed the theory of reasoned action (Ajzen and Fishbein, 1980) to examine the influence of trust in and attitude toward the online store on consumers' purchase intentions (e.g., Jarvenpaa and Tractinsky. 1999: McKnight et al.. 2002; Shim et al. 2001). However, although online shopping includes hedonic and utilitarian dimensions (Bridges and Florsheim, 2008: Childers et al., 2001), few studies have deconstructed consumer attitudes in this context to examine the antecedents and influence of attitude toward the online store as a multi-dimensional construct. Second, researchers maintain that consumers' perceived congruity between the two stores positively influences the formation of trust in and attitude toward the multichannel retailer's online store (e.g., Badrinarayanan et al., 2012; Kwon and Lennon, 2009; Wang et al. 2009). However, a majority of these studies have 
conceptualized congruity between the two stores as a holistic construct and few studies have compared congruity on an attribute-by-attribute basis (e.g., Verhagen and van Dolen, 2009). Third, past research suggests that congruity between consumers ${ }^{\prime}$ self-image and perceived store image plays an important role in the formation of trust in and attitude toward retailers (e.g., Kang et al., 2009; Kressmann et al., 2006). Yet, few studies have incorporated congruity between consumers' self-image and perceived image of the online store of a multichannel retailer in their theoretical frameworks.

Addressing these issues, this study develops a framework in which (a) trust and attitude (conceptualized as a second-order construct with hedonic and utilitarian dimensions) influence purchase intentions, (b) congruity between the multichannel retailer's land-based and online stores (conceptualized as a second-order constructs made up of seven dimensions: aesthetic appeal, navigation convenience, transaction convenience, atmosphere, service, price orientation, and security) influences trust in and attitude toward the online store, and (c) congruity between consumers ${ }^{\prime}$ self-image and perceived image of the online store influences trust in and attitude toward the online store. The framework is then tested using data collected from 316 respondents. The findings indicate that the two congruity variables are critical for influencing purchase intentions in online stores of multichannel retailers, albeit through different routes. Specifically, the results indicate that congruity between the land-based and online stores of multichannel retailers is necessary for the formation of trust in the online store, whereas congruity between selfimage and image of the online store is necessary for the formation of trust in and attitude toward the online store. In the following sections, the theoretical framework is developed and appropriate hypotheses are offered. Subsequently, the data collection and analysis procedures are discussed. Based on the study's results, theoretical contributions and implications for multichannel retailers are presented. Finally, limitations of the study and directions for future research are summarized.

\section{Framework development and hypotheses}

Fig. 1 represents the framework developed in this study. The development of the framework and relevant hypotheses are discussed in four phases. First, the relationships between trust in, attitude toward, and purchase intentions in online stores of multichannel retailers are discussed. Second, the role of congruity between the land-based and online stores of multi-channel retailer is examined. Third, the role of congruity between consumers' self-image and perceived image of the online store is examined. Fourth, the control variables are discussed.

\subsection{Trust, attitudes, and purchase intentions}

The theory of reasoned action (TRA) posits that a person's beliefs about the nature of anticipated outcomes influence the formation of attitudes toward behavior, which in turn, influence behavioral intentions (Ajzen and Fishbein, 1980). Several studies have employed TRA in the online shopping context and have examined the interrelationships between three focal constructs: trust, attitude, and purchase intentions (e.g., Badrinarayanan et al., 2012; Ha and Stoel. 2009). Trust, the belief or expectation that a store will meet its commitments (e.g., Eastlick et al, 2006), is often considered as a determining factor in influencing consumers' online perceptions and behavior (e.g., McCole et al., 2009). When consumers trust an online store to be reliable and credible, they are likely to develop favorable attitudes toward that store and, ultimately, intentions to make purchases in that store (e.g., Ha and Stoel, 2009).

Although past researchers have consistently demonstrated that attitude toward the online store, i.e., an individual's favorable or unfavorable evaluations of the store, is positively related to purchase intentions, very few studies have incorporated the premise that attitude in the context of online shopping includes both utilitarian and hedonic dimensions (e.g., Bridges and Florsheim, 2008; Childers et al., 2001). The utilitarian dimension is based on evaluation of various functions provided by the online store, whereas the hedonic dimension is based on sensations derived from the online shopping experience (Voss et al., 2003). Research on online shopping behavior supports that the functionalities of online stores do not adequately explain predispositions to shop online and that, with contemporary online shoppers being accustomed to the online shopping process, the consideration of experiential elements is also warranted to fully understand attitude development (Bridges and Florsheim. 2008). In the context of online stores of multichannel retailers, utilitarian attitude may result from evaluations of functions such as information, selection, availability, accessibility, and ease of use, among others (Bridges and Florsheim, 2008; Childers et at., 2001). In contrast, hedonic attitude may result from experiences of fun, playfulness, arousal, and positive affect (Bridges and Florsheim, 2008; Childers et al., 2001). The conceptualization of consumer attitudes toward the online store as a second-order construct made up of hedonic and utilitarian dimensions, therefore, could enable a better understanding of the complexities of the attitude formation process as well as the influence of each unique dimension on purchase intentions (Voss et al. 2003). Extending prior empirical research on the relationships between trust in, attitude toward, and purchase intentions in online stores of multichannel retailers (e.g., Badrinarayanan et al., 2012; Ha and Stoel, 2009) by conceptualizing attitude as a second-order construct made up of hedonic and utilitarian dimensions, the following hypotheses are offered:

H1:. Consumers' trust in the online store of a multichannel retailer is positively related to their attitude toward that online store (secondorder construct composed of hedonic and utilitarian dimensions)

H2:. Consumers' trust in the online store of a multichannel retailer is positively related to their purchase intentions in that online store

H3:. Consumers attitude toward the online store (second-order construct composed of hedonic and utilitarian dimensions) of a multichannel retailer is positively related to their purchase intentions in that online store

\subsection{Congruity with land-based store}

Research on online stores of multichannel retailers indicates that consumers' beliefs and attitudes are (a) formed as a result of exposure to the retailer's online store and (b) carried forward from prior experiences with the retailer's land-based store (Kwon and Lennon, 2009: Wang et al., 2009). That is, in addition to evaluating a multichannel retailer's online store based on its idiosyncratic characteristics, consumers are likely to compare the online store to their existing image of the retailer's land-based store (e.g., Badrinarayanan et al., 2012; Kwon and Lennon, 2009; Wang et al., 2009). When characteristics of the online store match consumers ${ }^{\prime}$ expectations about the retailer, congruity, i.e., the perceived similarity or mismatch in salient store related attributes, exists. Cognitive consistency theories, such as categorization theory (Stjan, 1985), support that perceived congruity between a known object or category (the multichannel retailer's land-based store in this case) and a new stimulus (the retailer's online store) 


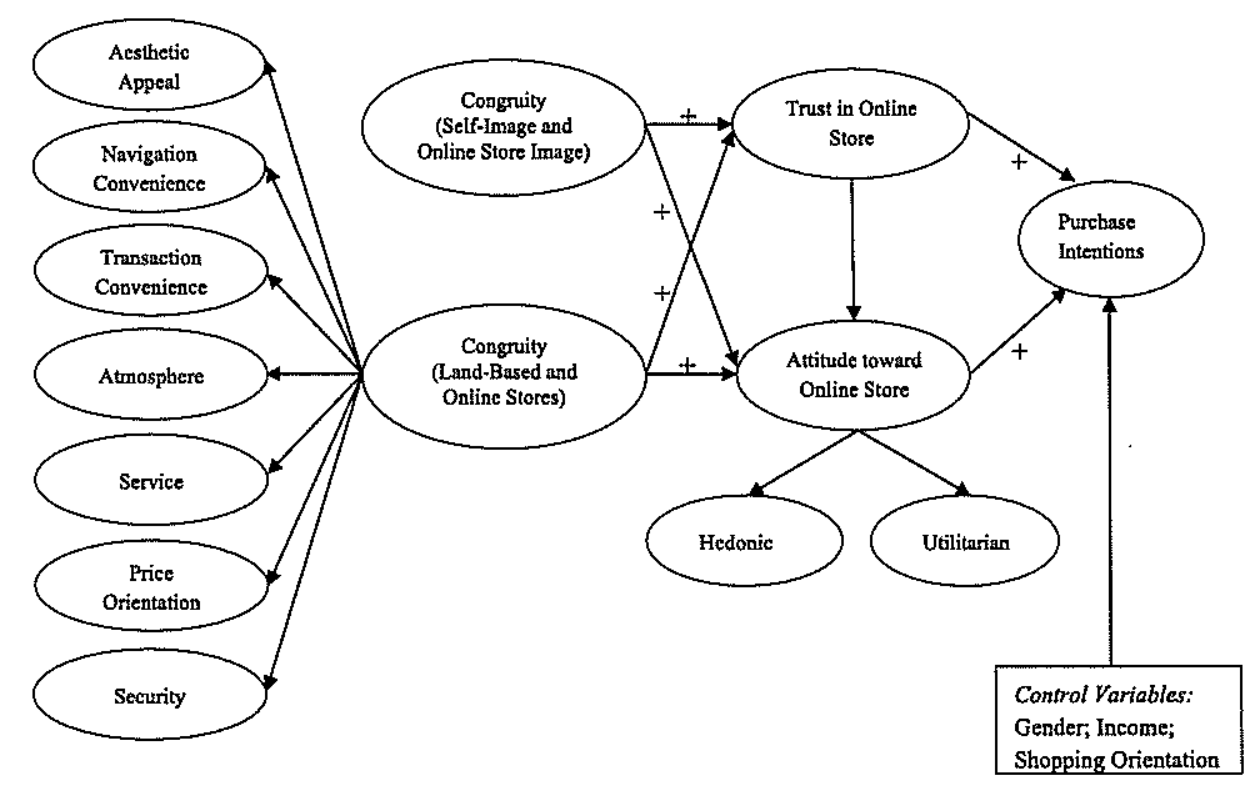

Fig. 1. The hypothesized model.

influences consumers' evaluations of and attitude toward the new stimulus. Badrinarayanan et al. (2012) offer empirical support for the argument that perceived image congruity between a multichannel retailer's land-based and online stores influences trust in and attitude toward the online store.

However, a majority of extant studies in this domain have conceptualized image congruity as a unidimensional construct and have not examined whether congruity in specific storerelated dimensions exert varying impact on trust in and attitude toward the online store. Yet, several seminal studies on land-based and online retailing have argued for the importance of verifying store image formation on an attribute-by-attribute basis (e.g., Lindquist 1974775; Page and Lepkowska-White, 2002). Studying image congruity using an attribute-by-attribute approach would enable multichannel retailers to better manage and leverage consumers' perceptions regarding salient store-related attributes. This approach has been adopted in prior studies on the influence of retailer characteristics on shopper attitude and behavior. For instance, Jinfeng and Zhilong (2009) discuss convenience, institutional factors, physical facilities, perceived price, and employee service as key characteristics of hypermarkets that influence awareness, associations, and perceived quality perceptions. Likewise, Thang and Tan (2003) use merchandising, store atmosphere, in-store service, accessibility, reputation, promotion, facilities and post-transaction service as key retailer characteristics that influence consumer perceptions and shopping intentions in their study on department stores. Specifically, in the context of online versus offline stores, Katerattanakul and Siau (2003) provide insight on the correspondence between characteristics of online and offline stores. According to their work, site and system features of online stores correspond to physical facilities of offline stores; product and promotion information provided in online stores correspond with merchandise and promotion activities seen in offline stores; appearance and congeniality of online stores correspond to clientele and store atmosphere in offline stores; and transaction service, satisfaction, convenience, and institutional factors in online stores are directly comparable to their counterparts in offline stores.

Similarly, in this study, image congruity between a multichannel retailer's online and land-based stores is conceptualized as a higher order factor with the following sub-dimensions: aesthetic appeal, navigation convenience, transaction convenience, atmosphere, service, price orientation, and security. Although it is acknowledged that there are other store dimensions than the ones mentioned above, the current dimensions are selected so as include representative functional (e.g., navigation, convenience, etc.) and experiential (e.g., aesthetic appeal, atmosphere, etc.) features that can be compared across both online and land-based stores. Further, these sub-dimensions have been consistently found to influence trust in and attitude toward land-based and online retailers (Ganesh et al., 2010; Kwon and lenmon, 2009; Verhagen and van Dolen. 2009). Accordingly, congruity between a multichannel retailer's land-based and online stores, based on consumers' perceptions across the seven dimensions enumerated above, is hypothesized to influence trust in and attitude toward the retailer's online store. That is:

H4: Consumers' perceived congruity between a multichannel retailer's online and land-based stores (on aesthetic appeal, navigation convenience, transaction convenience, atmosphere, service, price orientation, and security dimensions) is positively related to their trust in the multichannel retailer's online store

H5: Consumers' perceived congruity between a multichannel retailer's online and land-based stores (on aesthetic appeal, navigation convenience, transaction convenience, atmosphere, service, price orientation, and security dimensions) is positively related to their attitude toward the multichannel retailer's online store

\subsection{Congruity between self-image and online store image}

Self-image congruity refers to the perceived match between consumers' image of themselves (i.e., self-concept) and their image of a product, brand, store, or other focal entities (Sirgy and Samli 1985; Wang et al., 2009). Past research has identified that self-image congruity influences outcomes such as choice, preference, attitude, satisfaction, and loyalty with respect to products, brands, and retail stores (Sirgy and Samli, 1985). Yet, very few studies have explored self-image congruity in the context of online shopping (e.g., Kang et al., 2009). Research on self-image congruity suggests that consumers are likely to choose and patronize online stores which reflect personalities that match their self-image or ideal selves (Kressmann et al., 2006; Sirgy 
and Samli, 1985). In a similar vein, it is expected that congruity between consumers' self-image and their image of online stores of multichannel retailers is likely to be positively related to trust in and attitude toward that online store. That is:

H6:. Consumers' perceived congruity between their self-image and the image of the online store of a multichannel retailer is positively related to their trust in that online store

H7:. Consumers' perceived congruity between their self-image and the image of the online store of a multichannel retailer is positively related to their attitude toward that online store

\subsection{Control variables}

Several past studies on demographics and the Internet indicate that gender and income are correlated with the use of the Internet and purchase intentions in online stores (e.g., Schlosser et al., 2006). Likewise, individual differences in attitude toward and intensity of shopping may also influence purchase intentions, with compulsive shoppers seeking to obtain gratification from the shopping process itself ( $0^{\prime} G$ uinn, Faber 1989). Therefore, to provide a more robust test of the proposed framework, the influence of gender, income, and shopping behavior on purchase intentions is controlled.

\section{Method}

\subsection{Data collection}

Data was collected from 316 respondents who were enrolled in a multiple sections of an introductory marketing course at a large southwestern U.S. university. This population was deemed appropriate as $54 \%$ of adults in the U.S. aged 18-30 are reported to shop online at least quarterly (Internet Retailer, 2013). An online survey was administered and respondents were provided with extra credit for participation. A majority of the respondents was male (54.4\%), between 18 and 24 years old (86.7\%), and white (69.6\%). The questionnaire provided detailed instructions, stated that the objective was to gather information about respondents' experience with multichannel retailers, and listed examples of multichannel retailers. Respondents were queried about their online shopping behavior and purchase experience. Next, they were asked whether they have shopped in online stores of multichannel retailers, and if so, to type the name of their favorite multichannel retailer and answer questions regarding perceived congruity between that multichannel retailer's land-based and online stores. Subsequently, after asking respondents to restate the online store of their favorite multichannel retailer, they were requested to answer questions on perceived congruity between their self-image and the image of the online store, trust in and attitude toward the online store, and intentions to purchase in that online store.

\subsection{Measures}

Established measures were utilized to measure all constructs. Trust in the online store was measured using a five-item, sevenpoint, Likert scale borrowed from research on online consumer behavior (e.g. Jarverpad and Tactinsky. 1999). As noted earlier, attitude toward the online store is conceptualized in this study as a second order construct with two reflective dimensions, with each dimension measured using reflective indicators. Accordingly, the utilitarian and hedonic dimensions of attitude were measured using a five-item, seven-point, semantic-differential scale (e.g. effective-ineffective; dull-exciting) (e.g., Voss at al., 2003). Congruity between the multichannel retailer's land-based and online stores was conceptualized as a second order construct with seven reflective dimensions (aesthetic appeal, navigation convenience, transaction convenience, atmosphere, service, price orientation, and security), with each dimension measured using reflective indicators. Each dimension was measured using multi-item, seven-point, semantic differential scales derived from published research (e.g., Ganesh et al., 2010; Kwon and lennon, 2009). Congruity between self-image and image of the online store of the multichannel retailer was measured using a four-item, seven point, Likert scale adapted from prior research on self-image congruity (Kang et al., 2009; Sirgy et al., 1997). Purchase intentions was measured using a three-item, seven-point, semantic differential scale that measured respondents' likelihood, possibility, and probability of making purchases in the online store of their favorite multichannel retailer (Badrinarayanan et al., 2012). Shopping orientation was measured using the compulsive buying scale (Ridgway et al., 2008) composed of four seven-point, Likert scaled items and two seven-point, semantic-differential scaled items. Personal income was measured using a suitable interval scale and gender was measured using a categorical scale (male represented by 1 and female by 2 ).

\section{Analysis and results}

The internal and external consistency of the second-order model (see Fig. 1) was assessed using confirmatory factor analysis with LISREL 8.72 (Jöreskog \& Sörbon, 1989). The fit indices $\left(\chi^{2}=1832.42, \chi^{2} / \mathrm{df}=1.83 ; \mathrm{RMSEA}=0.051, \mathrm{SRMR}=0.056 ; \mathrm{GFI}=0.80 ;\right.$ $\mathrm{CFl}=0.97 ; \mathrm{NNFl}=0.97$ ) were within acceptable ranges (Hu and Bentler 1999) and all factor loadings were statistically significant $(p<.01$, t-values ranging from 8.04 to 29.33$)$. The composite reliabilities ranged from. 82 to. 92 , except for purchase intentions $(.77)$ and attitude towards the online store $(.60)$. In addition, the average variance extracted (AVE) for all constructs, except for attitude toward the online store (.44) and shopping orientation (.49), were within acceptable ranges $(>.50)$. Individually, each of the two dimensions of attitude toward the online store, namely utilitarian and hedonic, has acceptable composite reliability $(.89$ \& .92 , respectively) and AVE (.67\& .75, respectively) values. These values suggest that the indicators of the two dimensions of attitude are consistent in their measurement of their respective constructs (Fornell and Larcker; 1981), although when the two constructs were theorized to be part of a second order construct, the composite reliability and AVE values were somewhat low as the second order construct was measured by only two composite indicators representing each of the dimensions. Furthermore, the AVEs were substantially higher than the squared correlation between the constructs and all other constructs, except for congruity between the land-based and online stores and attitude toward the online store. Both second order constructs displayed AVEs slightly lower or higher than the average correlation of their reflective constructs (see Appendix A). However, their AVEs were higher than the squared correlations of most of the other constructs. Overall, these results suggest adequate unidimensionality, discriminant validity, and composite reliability to proceed further with the analysis (Bagozzi, Youjae 1988: Fornell and Larcker. 1981).

Structural equation modeling (e.g., Bollen, 1989; Byrne, 1998; Hancock and Mueller 2006) was employed to test the proposed framework (see Table 1). The model displayed adequate fit indices $\left(\chi^{2}=1837.75, \chi^{2}\right) \mathrm{df}=1.82 ; \mathrm{RMSEA}=0.051$, SRMR $=0.059$; $\mathrm{GFI}=0.80 ; \mathrm{CFI}=0.97 ; \mathrm{NNFI}=0.97$ ). Trust in the online store exerted a significant direct influence $(p<.001)$ on attitude toward the online store as proposed in $H 1$, but no influence on purchase intentions as hypothesized in 12 . However, trust in the online store exerted a significant indirect effect through attitude toward 
Table 1

Results.

\begin{tabular}{|c|c|}
\hline Effects' & Value (C.R.") \\
\hline \multicolumn{2}{|l|}{ Direct effects' } \\
\hline HI: Trust on attitude & $.48(4.36)^{k_{t}}$ \\
\hline H2: Trust on purchase intentions & $-.08(0.64)$ \\
\hline H3: Attitude on purchase intentions & $.57(4.01)^{*}$ \\
\hline H-: Congruity with land-based on trust & $.32(5.93)^{4}$ \\
\hline H5: Congruity with land-based on attitude & $.10(1.49)$ \\
\hline H6: Congruity with self-image on trust & $.46(7.67)^{*}$ \\
\hline H7: Congruity with self-image on attitude & $.35(3,86)^{*}$ \\
\hline Gender on purchase intentions & $-.02(-0.28)$ \\
\hline Income on purchase intentions & $.11(1.93)$ \\
\hline Shopping orientation on purchase intentions & $.02(0.34)$ \\
\hline \multicolumn{2}{|l|}{ Total effects" } \\
\hline Trust on attitude & $.48(4.36)^{n}$ \\
\hline Trust on purchase intentions & $.19(2.54)^{\text {s.th }}$ \\
\hline Attitude on purchase intentions & $.57(4.01)^{*}$ \\
\hline Congruity with land-based on trust & $.32(5.93)^{*}$ \\
\hline Congruity with land-based on attitude & $.26(3.32)^{*}$ \\
\hline Congruity with self-image on trust & $.46(7.67)^{*}$ \\
\hline Congruity with self-image on attitude & $.57(5.29)^{*}$ \\
\hline Gender on purchase intentions & $-.02(-0.28)$ \\
\hline Income on purchase intentions & $.11(1.93)$ \\
\hline Shopping orientation on purchase intentions & $.02(0.34)$ \\
\hline Congruity with land-based on purchase intentions & $.12(2.82)^{* 3}$ \\
\hline Congruity with self-image on purchase intentions & $.29(4.65)^{8}$ \\
\hline \multicolumn{2}{|l|}{ Other effects } \\
\hline Utilitarian perceptions-attitude & $.68(6.68)^{*}$ \\
\hline Hedonic perceptions-attitude & $.64(6.58)^{n}$ \\
\hline Aesthetic appeal-congruity with land-based & $.76(10.59)^{\star 4}$ \\
\hline Navigation convenience-congruity with land-based & $.81(12.36)^{x \prime}$ \\
\hline Transaction convenience-congruity with land-based & $.78(12.37)^{\prime \prime \prime}$ \\
\hline Atmosphere-congruity with land-based & $.85(14.39)^{k}$ \\
\hline Service-congruity with land-based & $.82(14.56)^{*}$ \\
\hline Price orientation-congruity with land-based & $.72(11.75)^{*}$ \\
\hline Security-congruity with land-based & $.78(13.08)^{*}$ \\
\hline
\end{tabular}

${ }^{2}$ Model goodness of fit indices: $\chi^{2}=1837.75, \chi^{2} / \mathrm{df}=1.82 ;$ RMSEA $=0.051$ $\mathrm{SRMR}=0.059 ; \mathrm{GFI}=0.80 ; \mathrm{CF}=0.97 ; \mathrm{NNF}=0.97$.

${ }^{b}$ Critical ratio (t-values).

'Standardized solution.

* $p<.01$.

$\bullet p<.001$.

the online store $(p<.001)$ and total effect $(p<.001)$ on purchase intentions, suggesting that attitude toward the online store mediates the effect of trust on purchase intentions. Attitude toward the online store exerted a significant direct influence $(p<.001)$ on purchase intentions, thereby supporting $\mathrm{H} 3$.

Congruity between a multichannel retailer's land-based and online stores exerted a significant effect $(p<.001)$ on trust in the online store, but did not exert a significant direct effect on attitude toward the online store. That is, $\mathrm{H} 4$ was supported whereas 115 was not. However, congruity between a multichannel retailer's land-based and online stores exerted a significant indirect effect through trust in the online store $(p<.001)$ and total effect $(p<.001)$ effect on attitude toward the online store, suggesting that trust mediates the effect of this congruity variable on attitude toward the online store. Self-image congruity, or the perceived congruity between consumers' self-image and their image of the online store of a multichannel retailer, was found to be significantly related to both trust $(p<.001)$ in and attitude $(p<.001)$ toward the online store, thereby lending support for hypotheses 136 and 17 . None of the control variables (gender, income, and shopping orientation) had any significant effect on purchase intentions.

The utilitarian $(p<.001)$ and hedonic $(p<.001)$ dimensions had significant effects on attitude toward the online store. Similarly, each retailer-related dimension (aesthetic appeal, navigation convenience, transaction convenience, atmosphere, service, price orientation, and security) exerted significant effects $(p<.001)$ on perceived congruity between a multichannel retailer's land-based and online stores. Attitude toward the online store exerted the greatest total significant effect (.57) on purchase intentions, followed by congruity between self-image and image of the online store (.29), trust in the online store (.19), and congruity between the land-based and online stores (.12). Further, congruity between the land-based and online stores exerted a significant $(p<.001)$ total effect on the utilitarian and hedonic dimensions of the attitude toward the online store. Similarly, congruity between self-image and image of the online store as well as trust in the online store also exerted significant $(p<.001)$ total effects on both attitude dimensions.

\section{Discussion and implications}

Recent industry reports indicate that online stores of multichannel retailers continue to underperform compared to pure Internet retailers in terms of compounded annual growth rate, consumers' patronage and purchase intentions, and sales. Therefore, although researchers have investigated the phenomenon of erstwhile land-based retailers transforming into multichannel retailers for more than a decade, more rigorous research attention is warranted. Specifically, this study empirically tested a framework in which (a) trust and attitude (conceptualized as a secondorder construct with hedonic and utilitarian dimensions) influence purchase intentions, (b) congruity between the multichannel retailer's land-based and online stores (conceptualized as a second-order constructs made up of seven dimensions: aesthetic appeal, navigation convenience, transaction convenience, atmosphere, service, price orientation, and security) influences trust in and attitude toward the online store, and (c) congruity between consumers' self-image and perceived image of the online store influences trust in and attitude toward the online store. By developing and testing a parsimonious, yet expanded, model of purchase intentions in online stores of multichannel retailers, this study contributes to the extant literature on multichannel retailers and offers actionable recommendations for such retailers to compete better.

First, this study confirms the appropriateness of the theory of reasoned action in the context of online stores of multichannel retailers. Consistent with the theory, trust in the online store was found to be positively related to attitude toward the online store, which in turn was positively related to purchase intentions. In fact, among all the factors included in the framework, attitude toward the store exerts the greatest influence on online purchase intentions. However, our framework adds more depth to testing the theory of reasoned action in the context of online stores of multichannel retailers by introducing the notion of secondorder factors for attitude toward the online store and consumers' perceived congruity between a multichannel retailer's land-based and online stores. The results of our research provide support for conceptualizing and testing the underlying dimensions of attitude (e.g., Voss et al., 2003) and store image (e.g., Katerattankul and Siau 2003; Jinfeng and Zlislong, 2009) and, consequently, suggest that the respective characteristics must be understood at a greater level of specificity than the holistic approach suggested in extant research (e.g., Badrinarayanan et al., 2012).

Specifically, the results provide support for the second-order factor structure of consumer attitudes, which is reflected in two first-order factors: hedonic and utilitarian attitudes. This indicates that multichannel retailers need to focus on the components of attitude toward their online store rather than assuming that attitude formation is a holistic process. Utilitarian attitudes refer to consumers' rational evaluations and predispositions that result from the completion of their shopping tasks in an efficient and 
timely manner without any irritations (Childers et al., 2001). To facilitate the formation of utilitarian attitudes, multichannel retailers must therefore focus on how their online stores facilitate the shopping process and identify ways to enhance consumer utility by leveraging the integration between their land-based and online stores (e.g., browsing/pick-up/return options that cannot be provided by pure Internet retailers). Hedonic attitudes refer to consumers' personal or subjective evaluations and predispositions that result from the fun, entertainment, and playfulness derived from the shopping experience, rather than any specific goal achievement (Childers et al., 2001). To facilitate the formation of hedonic attitudes, online stores of multichannel retailers must focus on making the shopping experience an enjoyable one and incorporate sensory cues that are offered by prototypical online stores (e.g., personalization, product trial, real-time interaction, avatars, and other sensory stimuli that influence enjoyment or excitement).

Second, this study complements prior research on the importance of consumers' perceived congruity between a multichannel retailer's land-based and online stores (e.g., Badrinarayanan et al., 2012; Kwon and Lennon, 2009). Although a direct relationship between this congruity variable and attitude toward the online store was not supported, a significant and positive relationship was supported with trust in the online store. This finding implies that multichannel retailers must monitor, maintain, and improve the perceived fit between the images of their two stores to facilitate trust formation in their online stores. In addition, the results provide support for the second-order factor structure of consumers' perceived congruity between a multichannel retailer's land-based and online stores, which is reflected in seven firstorder factors: aesthetic appeal, navigation convenience, transaction convenience, atmosphere, service, price orientation, and security. As all seven factors exhibit high factor loadings, an implication for multichannel retailers is that they must identify store-related attributes that are salient to their shopper segments and strive for establishing and communicating consistency on those attributes to their online customers.

Third, this study incorporated research on self-image congruity to better understand trust and attitude formation in online stores of multichannel retailers. Although past studies demonstrate that consumers select products, brands, retailers, and online stores based on assessments of congruity between their images of such entities and their self-image (e.g., Kang et al., 2009; Sirgy and Samli 1985), self-image congruity has not been explored thus far in the context online stores of multichannel retailers. The results show that self-image congruity is positively related to both trust in and attitude toward the online store. After attitude toward the online store, self-image congruity exerts the highest influence on online purchase intentions. This indicates that, in addition to making sure perceived congruity exists between their land-based and online stores, multichannel retailers must carefully design their online stores so that it is consistent with the self-images of their shopper segments.

Overall, the results of the empirical test provide robust support to the framework developed in this paper. Although two of the proposed hypotheses were not supported, the total effects of all of variables in the framework were found to be significant. The framework and the results of the empirical test suggest that our study is a step in the right direction. Specifically, given that attitude and congruity were historically conceptualized and measured as holistic constructs, academics and practitioners should note that viewing attitude and congruity from a multidimensional perspective should be actively pursued and could prove beneficial for the online stores of multichannel retailers. This study conceptualizes and measures attitude and congruity as second order constructs and, therefore, provides initial evidence for why these constructs merit multi-dimensional conceptualizations and measures. However, we do acknowledge that our framework is just the beginning and hope that it acts as a catalyst for future research. Accordingly, we invite empirical and conceptual scrutiny of our framework and believe that future research can critically evaluate our work in order to build strong theoretical foundations for research on online stores of multichannel retailers.

\subsection{Limitations and directions for future research}

Though we find robust support for the proposed framework, this study is not without limitations. Specifically, our framework is neither exhaustive nor comprehensive. However, it provides strong foundations for theory development with reference to purchase intentions in online stores of multichannel retailers. Potentially, first, future research could add several variables that are specific to online stores of multi-channel retailers. For example, some multichannel retailers are better than others in creating synergy between the two store formats by allowing customers to purchase merchandise online and pick-up or return offline. Similarly, online stores of multichannel retailers often indicate whether an item being browsed is available in an offline store within proximity of a customer's physical location. It would be interesting to verify whether perceived synergy in transactions complement shoppers' perceived congruity in engendering purchase intentions. In addition, website appearance, entertainment value, informational assistance, transaction capability, response time, and trust in online transactions have been identified in prior research as unique dimensions affecting transactions in online retailers (e.g., Kim and Stoel, 2004). Although it is not feasible to measure congruity across dimensions that are unique to offline (e.g., parking, lighting, etc.) and online (e.g., page loading or refresh time, pop-ups, etc.), we urge that dimensions pertinent to online stores be incorporated in future frameworks on online purchase intentions as moderators or control variables. Second, future research could conceptualize attitude and congruity as multidimensional but not as second-order constructs. We acknowledge that such conceptualization and measurement could provide additional depth to our framework. Third, future research could provide a deeper understanding of the seven dimensions of congruity, i.e., aesthetic appeal, navigation convenience, transaction convenience, atmosphere, service, price orientation, and security that were included in this study. For example, it would be worthwhile to explore specific antecedents and consequences of the seven dimensions. Similar research could also be done with reference to hedonic and utilitarian dimensions of attitude. Fourth, future research could investigate multi-dimensional nature of congruity and attitude in the context of pure Internet retailers that become multi-channel retailers. Fifth, as this study did not examine retailer-specific differences, future researchers could verify whether the proposed relationships hold across different retailer types and sizes, products carried, brand assortment, and other characteristics.

Further, to improve the generalizability of the findings, different samples and respondent profiles could be used. Although this study used seven dimensions for perceived congruity between the land-based and online stores of multichannel retailers, other dimensions can be incorporated in future studies (e.g., brands carried, discounting strategies, sales promotions, etc.). Shopping orientation was used here as a control variable. However, future researchers can examine whether rational and compulsive shoppers differ in terms or congruity assessments, trust and attitude formation, and intentions to purchase in online stores of multichannel retailers. It would be interesting to compare the framework across multichannel retailers in business-to-consumer and business-to-business settings to verify whether certain 
Table A1

Reliability and validity.

\begin{tabular}{|c|c|c|c|c|}
\hline Constructs and measures & $\begin{array}{l}\text { Factor } \\
\text { loading }\end{array}$ & $\begin{array}{l}\text { Composite } \\
\text { reliability }\end{array}$ & $\begin{array}{l}\text { Average variance } \\
\text { extracted }\end{array}$ & Squared correlation with other constructs \\
\hline Congruity (Land-based and online stores) (second order construct) & & 0.92 & 0.62 & $.65(\mathrm{NC}) ; .72(\mathrm{AT}) ; .67(\mathrm{SVC})$ \\
\hline Aesthetic appeal (AP) & 0.76 & & & \\
\hline Navigation convenience (NC) & 0.81 & & & \\
\hline Transaction convenience (TC) & 0.78 & & & \\
\hline Atmosphere (AT) & 0.85 & & & \\
\hline Service (SVC) & 0.82 & & & \\
\hline Price orientation (PO) & 0.72 & & & \\
\hline Security (SCT) & 0.78 & & & \\
\hline Aesthetic appeal (AP) & & 0.83 & 0.61 & $.42(\mathrm{AP})$ \\
\hline The feel of the stores & 0.7 & & & \\
\hline The visual images used & 0.81 & & & \\
\hline Display of products in store & 0.84 & & & \\
\hline Navigation convenience (NC) & & 0.86 & 0.67 & .65 (Congruity between land-based and online stores) \\
\hline Ease of finding what you looking for & 0.76 & & & \\
\hline Ease of navigating around store & 0.88 & & & \\
\hline Extend to which stores are organized & 0.80 & & & \\
\hline Transaction convenience (TC) & & 0.89 & 0.75 & .60 (Congruity between land-based and online stores) \\
\hline Ease of purchasing items in stores & 0.78 & & & \\
\hline Ease of paying for items in stores & 0.93 & & & \\
\hline Ease of completing transactions in stores & 0.87 & & & \\
\hline Atmosphere (AT) & & 0.90 & 0.76 & .72 (Congruity between land-based and anline stores) \\
\hline How fun the stores are & 0.82 & & & \\
\hline How attractive the stores are & 0.92 & & & \\
\hline How pleasurable the stores are & 0.88 & & & \\
\hline Service (SVC) & & 0.87 & 0.70 & 67 (Congruity between land-based and online stores) \\
\hline How friendly the service is ${ }^{i}$ & $s$ & & & \\
\hline How helpful the service is & 0.88 & & & \\
\hline How good the service is & 0.91 & & & \\
\hline How knowledgeable the service providers are ${ }^{a}$ & 2 & & & . \\
\hline How fast the service is & 0.70 & & & \\
\hline Price orientation (PO) & & 0.88 & 0.71 & S1(Congruity between land-based and online stores) \\
\hline The availability of special deals & 0.82 & & & \\
\hline Notices about sales or new products & 0.90 & & & \\
\hline The frequency of sales or special deals & 0.81 & & & \\
\hline Security (SCT) & & 0.91 & 0.78 & 60(Congruity between land-based and online stores) \\
\hline The safety offered by stores & 0.82 & & & \\
\hline The security provided for shoppers & 0.91 & & & \\
\hline The security provided for transactions & 0.91 & & & \\
\hline Congruence (Self-image and online store image) & & 0.87 & 0.7 & .45 (Attitude) \\
\hline The online store's image is consistent with my setf-image & $\therefore$ & & & \\
\hline The online store reflects who I am & 0.70 & & & \\
\hline People similar to me use this online store & 0.92 & & & \\
\hline The ather shoppers who use this online store are similar to me & 0.88 & & & \\
\hline Trust in the online store & & 0.95 & 0.78 & .54 (Attitude) \\
\hline The online store is reliable & 0.89 & & & \\
\hline The online store is trustworthy & 0.94 & & & \\
\hline The only store is dependable & 0.96 & & & \\
\hline The online store secures my personal information & 0.86 & & & \\
\hline I would recommend the online store to my friends & 0.76 & & & \\
\hline Attitude toward the online store (second order construct) & & 0.61 & 0.44 & .54 (Trust); .44 (Self-image congruity and online \\
\hline Utilitarian perceptions of online store (UT) & 0.67 & & & store image); 44 (Utilitarian) \\
\hline Hedonic perceptions of online store (HE) & 0.65 & & & \\
\hline Utilitarian perceptions of online store (UT) & & 0.89 & 0.67 & .44 (Attitude) \\
\hline Effective-ineffective & 0.87 & & & \\
\hline Helpful-unhelpful & 0.73 & & & \\
\hline Functional-not functional & 0.92 & & & \\
\hline Necessary-unnecessary & 3 & & & \\
\hline Practical-impractical & 0.75 & & & \\
\hline Hedonic perceptions of online store (HE) & & 0.92 & 0.75 & .42 (Attitude) \\
\hline Fun-not fun & 0.85 & & & \\
\hline Dull-exciting & 0.89 & & & \\
\hline Delightful-not delightful & 0.89 & & & \\
\hline Thrilling-not thrilling & 0.83 & & & \\
\hline Enjoyable-not enjoyable: & 2 & & & \\
\hline Intention to purchase (IP) & & 0.78 & 0.55 & .26 (Attitude) \\
\hline Likely-unlikely & 0.56 & & & \\
\hline Probable-improbable & 0.72 & & & \\
\hline Possible-impossible & 0.9 & & & \\
\hline Shopping orientation (Comp) & & 0.82 & 0.49 & .09 (Attitude) \\
\hline My closet has unopened shopping bags in it & 0.66 & & & \\
\hline Others might consider me a "shopaholic" & 0.95 & & & \\
\hline Much of my life centers around buying things & 0.76 & & & \\
\hline I consider myself an impulse purchaser ${ }^{2}$ & -1 & & & \\
\hline I buy things I did not plan to buy & 0.55 & & & \\
\hline I buy things I don't need & 0.49 & & & \\
\hline
\end{tabular}

Goodness of fit indices: $\chi^{2}=1832.42, \chi^{2} / \mathrm{df}=1.83 ; \mathrm{RMSEA}=0.051, \mathrm{SRMR}=0.056 ; \mathrm{GFI}=0.80 ; \mathrm{CFI}=0.97 ; \mathrm{NNFI}=0.97$

a Deleted items. 
dimensions and/or relationships are unique to each context. In summary, this study offers theoretical and practical contributions regarding purchase intentions in online stores of multichannel retailers and calls for future researchers to engage in rigorous research to better understand this phenomenon and offer useful recommendations to multichannel retailers.

\section{Appendix A}

See Table Al.

\section{References}

Ajzen, i., Fishoin. A. 1980. Understanding Attitudes and Predicting Behavior. Prentice Hall, New Jersey

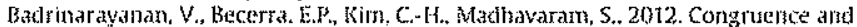
transferentes effects in online stores of multim alsmel fetailers: initial sevidence from the U.S. and South Korea. J. Acad. Marketing Sci 40 14), 539-557.

Bayozzi. R.. Youjase, $Y$., 1988 . On the evaluation of structural equation models. J. Acad. Marketin: Sci 16 (1), 74-94.

Bollen. K.A. 1989. Structural Equations with latent Variables. John Wilay s Solzs, New York

Brikges, E., Florslyeim, R. 2008. Hedonic and utilitarian shopping goals: the online experience. 1. Bus. Res. 61, 309-314.

Burne, $B$, M. 1998. Structural Gquation Modeling with LISRFL, PRELIS, and SIMPLIS: basic Concept5. Applications, and Progtamming. Lawrence Erbaum, New Jersey

Businessweek, (2012). "Why Wal-Mart is worried about Amazon," http://www. businessweek.comlarticles/2012-03-29/why-wal-mart-is-worried-about-ăma zon. Accessed, May 15, 2013.

Chiters, T.1., Carr. C.L., Peek. J. Carson, S., 2001. Hedonic and utilitarian metivations for online retail shopping belavior. J. Retailing 77, 517-535.

Eastlick, M.A., Lotz, S.L., Warrington, R. 2006. Understanding online B-to-C refationships: an integrated model of privacy concerns, trust, and commitment. J. Pus. kes. 59 (3), $8 \% 7-836$.

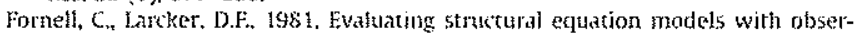
vable variables and meastrement eror. J. Marketing Res. is (1), 39-50.

Ganesh. J., Reynoless, K.E.. t.uckett, M., Pomirteanue, N., 2010, Online shopper motivations. and enstore attributes: an examination of online patronage behavior and shopper typologies. J. Rebaibing. 86 (1) 106-115.

Ha. S. Stot, L, 2009. Consumer e-shopping: aceptance: antececterts in a technolosy acceplince model. I. Bus. Ras, $62,565-571$.

Hanock. C.R. Mueller, R.O., 2006. Structural Equations: A Second Course Information Age Publishing Inc, Connecticut

Hu, L-T, Bentler. P.M. 1990. Cutoft criteria for fit indexes in tovariance structure andilysis: conventional criteria versts new alternatives. Struct, fictu, Model. $A$ Multidistiplinary folirnat 6 (1) $1-55$.

Internet Retailer, (2013). Trends and Data, thttp:/wwwinternetretaler.com/trends/ i. accessed May 15, 2013.

Jamenpad. S.1.., Tactinsky, N., 1990. Consumer trust in an Interget store: a crosscultural valtation. J. Comptut.-Mediat Communs. 5 (2), $1 \cdots 33$
Jinfene W, Zhilong, $T, 2009$, The impart of sefected store imatre dimensions on retniler equity: evidence from 10 Chinese hypermarkets. I. Retailing consum serv. $16(6), 436-454$

Jörestiog, K.G., Sörbom. D. 1989. LISREL 8 User's Reference Gude. Scientific Soltsware international, Illinois.

Kang. Y.S. Hong, S., 1ee. H., 2009. Exploring continued online service usatge bethavion: the roies of self-image congraity and regrtet, Comput. Hum. Behav $25,111-122$.

Katterattanakul, f.. Sjau, K., 2003. Creabing a virtual store inage, Communictaions of the $A C M+46(12), 226-232$.

Kim, 5. Stoel, l., 2004. Apparel retailers: weisite guality dimensions and satisfaction. J. Retailing Consum. Serv 11 (2). 109-117.

Kressmani, EM. Sirgy. J. Herman, A. Huber, F, Huber, S., Lee, D.J., 2006. Direct and indirect eflects of self inkage congruence on brand loyaty. . Bas. Res. 59, $955-964$.

Kwon, W. S., Lemon. S.J., 2009. What induces online toyalty? Onine versus offline brand imagres. 1. Bus. Res. 62. 557-564.

Lindquist, J.D., 1974/75. The meaning of image. J. Retailing 50 (4), 116 (29-38).

McCole. P.. Ramsey, E., Williams. j., 2009. Trust considerarions on attítudes cowards online purchasing; the moderating effect of privacy and sectrity concerns. I. Bus, Res, 63 (9-10), 1018-102-1.

McKnightt, D.H., Cloudhury. V.. Kacmur, C. 2002. Developing and validating trust mensures for e-commerce: an integrative typology. Informs. Syst Res, 13 (3). $334-359$.

Nielsen, (2010). Global Trends in Online Shopping: A Nielsen Global Consumer

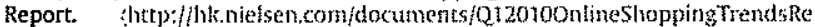
port.pdf:

OCtunt, T., Faber, R, 1989. Compulsive buying: a plienomenological exploration, J. Consum. Res. 16, 147-157 (September).

Page, C. tepkowska-White, E. 2002. Web equity: a framework for building consumer value in online companies. l. Consum, Marketing is (3), 231-248.

Ridgway, N.M. Kukar-Kinney. M. Monroe, K.B., 2008. An expanded concepecualizarion and a new messure of compulsive buying. I. Conswm. Res. 35 (4), 622-639.

Scliosser, A.E. White, TB. Loyd, S.M. 2006 , Corverting web site visitors into buyers: how web site investment increases consumer trusting foaliefs and ontine purchase intentions. J. Marketing $70(20), 133-118$.

Sbim. 5., Eastlick. A.A. Lotz, S.L.. Warrington, $P$, 2001. Al onlme prepurchase intentions modes: the role of intentions to search. 3 . Retailing. $77,397-416$

Sirgy. J.M., Sambli, CA., 1985. A path andytic model of store loyalty involving selfconerpt, store image, geographic loyalty, and socioecononic siatus. J. Acad. Aarketing Sti 13, 265-291 (Stmmer).

Sirgy, J.M., Grewal, D. Mangelburg. T.F, Park, 1.O., Chon, K., Claiborne, C.B., Johar. J.S., Berkmian, H. 1907 . Assessing the predictive validity of two methods of measuring setf-image congruence. ] Acat. Makdeting Sci $25(3), 229-241$.

Sujan. M. 1985. Constmer knowledge: effects on evaluation strategies mediang consurner judgmeglts. J. Consum. Ros. 12. 31 -46 (lune).

Thang D.C.L. Tan, B.1_B., 2003. Linking consumer pexception to preference of retail stores: an emptrical assessment of the multi-attributes of store image. J. Retailing Consum. Serv 10 (4). $793-200$.

Vertagen, T.. van Dolwa, W., 2009. Online purchase intentions: a multi-channel store image perspective. Inform. Manaye, 46, 77-82.

Voss, K.E., Spangenberg, E.R., Crohmann. B., 2003. Measuring the hedonic and atiltarian dimensions of consumer attitude. J. Markating Res, 10, 310-320.

Wang, S. Beatly, S.E.. Mothersbaugh, D.L.., 2009. Congraity's role in website attitude formation. ]. Bus, Res. \$2. 609-6) 